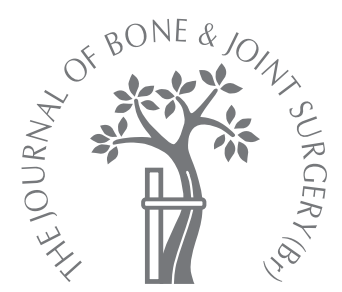

\title{
The effects of the short-term administration of low therapeutic doses of anti-COX-2 agents on the healing of fractures
}

\author{
AN EXPERIMENTAL STUDY IN RABBITS
}

T. Karachalios,

L. Boursinos,

L. Poultsides,

L. Khaldi,

K. N. Malizos

From the University of Thessaly, Larissa, Greece
- T. Karachalios, MD, DSc Associate Professor

L. Boursinos, MD, Resident - L. Poultsides, MD, Resident K. N. Malizos, MD, DSc, Professor and Chairman Orthopaedic Department L. Khaldi, MD, Consultant Pathologist

Department of Pathology School of Medicine, Faculty of Health Sciences, University of Thessaly, 22 Papakyriazi Street, Larisa 41222, Greece.

Correspondence should be sent to $\mathrm{Dr}$ T. Karachalios; e-mail: kar@med.uth.gr

(C2007 British Editorial Society of Bone and Joint Surgery doi:10.1302/0301-620X.89B9 $19050 \$ 2.00$

$J$ Bone Joint Surg $[\mathrm{Br}]$ 2007;89-B:1253-60. Received 18 December 2006; Accepted after revision 16 May 2007

We have evaluated the effect of the short-term administration of low therapeutic doses of modern COX-2 inhibitors on the healing of fractures.

A total of $\mathbf{4 0}$ adult male New Zealand rabbits were divided into five groups. A middiaphyseal osteotomy of the right ulna was performed and either normal saline, prednisolone, indometacin, meloxicam or rofecoxib was administered for five days. Radiological, biomechanical and histomorphometric evaluation was performed at six weeks.

In the group in which the highly selective anti-COX-2 agent, rofecoxib, was used the incidence of radiologically-incomplete union was similar to that in the control group. All the biomechanical parameters were statistically significantly lower in both the prednisolone and indometacin $(p=0.01)$ and in the meloxicam $(p=0.04)$ groups compared with the control group. Only the fracture load values were found to be statistically significantly lower $(p=0.05)$ in the rofecoxib group. Histomorphometric parameters were adversely affected in all groups with the specimens of the rofecoxib group showing the least negative effect.

Our findings indicated that the short-term administration of low therapeutic doses of a highly selective COX-2 inhibitor had a minor negative effect on bone healing.

Non-steroidal anti-inflammatory drugs (NSAIDs) are commonly prescribed for orthopaedic conditions such as osteoarthritis, soft-tissue injuries and fractures. ${ }^{1-5}$ The new generation of NSAIDs, selective cyclo-oxygenase-2 (COX-2) inhibitors, have analgesic and anti-inflammatory effects equivalent or superior to those of conventional NSAIDs, while reducing the prevalence of adverse gastrointestinal events. $^{1-7}$

Several animal and in vitro studies have shown impaired bone healing in the presence of conventional NSAIDs, as measured by a variety of different parameters. ${ }^{4,5,8-18}$ Initial studies investigating the effects of COX-2 selective inhibitors on bone healing yielded similar results, $5,16,19-22$ but some have shown minor or no impairment of the healing process. ${ }^{11,23,24}$

Since animal data suggest that the effects of COX-2 inhibitors are probably both dosedependent and reversible, ${ }^{1,3}$ we investigated the effect of the short-term administration of low therapeutic doses of corticosteroids, indometacin, meloxicam and rofecoxib on non-osteonal ${ }^{25}$ (secondary) healing of fractures in rabbits.

\section{Materials and Methods}

We used 40 adult male New Zealand white rabbits with a mean age of 3.0 months (2.3 to 3.1) and mean weight of $3.5 \mathrm{~kg}$ (3.4 to 3.6) at the start of the study. They were divided into five groups (A-E) of eight rabbits each and were kept under normal experimental conditions and allowed unrestricted access to standard stock diet and tap water. Six died during the induction of anaesthesia and a further 14, which were in groups B and C, developed superficial or deep infection. They were treated, withdrawn from the study and replaced by others. The experimental procedures had been reviewed and approved by an institutional animal care committee in accordance with the current National policy for experimentation in animals.

We performed an osteotomy at the middiaphysis of the right ulna on all the animals using a thin oscillating saw, ${ }^{26,27}$ under general anaesthesia induced by cetamine, mitazolam and atropine. Special care was taken to protect and avoid disruption of the periosteum at the site of the osteotomy which was left without fixation. All the animals were left free to move as pain allowed. All received two prophylactic 
Table I. Incidence of union, incomplete union and nonunion in the groups at six weeks

\begin{tabular}{llll}
\hline Group & Union & $\begin{array}{l}\text { Incomplete } \\
\text { union }\end{array}$ & Nonunion \\
\hline A. NaCl 0.9\% & 6 & 2 & - \\
B. Prezolon & 4 & 4 & - \\
C. Indometacin & 4 & 4 & - \\
D. Meloxicam & 5 & 3 & - \\
E. Rofecoxib & 6 & 2 & - \\
\hline
\end{tabular}

Table II. Mean $\left( \pm\right.$ SEM $\left.^{*}\right)$ value of the ratio of the diameter of the callus to the diameter of the bone $(\mathrm{dC} / \mathrm{dB})$ in the groups

\begin{tabular}{lc}
\hline Group & Ratio dC/dB \\
\hline A. NaCl 0.9\% & $1.73 \pm 0.084$ \\
B. Prezolon & $1.75 \pm 0.072$ \\
C. Indometacin & $1.99 \pm 0.097$ \\
D. Meloxicam & $1.95 \pm 0.080$ \\
E. Rofecoxib & $1.99 \pm 0.130$ \\
\hline${ }^{*}$ SEM, standard error of the mean
\end{tabular}

doses of antibiotic of $5 \mathrm{mg} / \mathrm{kg} / 24 \mathrm{hrs}$ of enrofloxacillin (Bayer/Veterin, Leverkusen, Germany), pre-operatively and on the first post-operative day.

In the animals of group A (control), five daily doses of $0.1 \mathrm{ml} / \mathrm{kg} / 24 \mathrm{hrs}$ of $\mathrm{NaCl} 0.9 \%$ were administered by intramuscular injection starting from the day of surgery. In group B, doses of $2.5 \mathrm{mg} / \mathrm{kg} / 24 \mathrm{hrs}$ of prednisolone (Nycomed, Linz, Austria) were administered intramuscularly. In group C, similar oral doses of $2 \mathrm{mg} / \mathrm{kg} / 24 \mathrm{hrs}$ of indometacin (Remek, Athens, Greece) were given using a veterinary drug administration mouth syringe. In group D, similar doses of $0.3 \mathrm{mg} / \mathrm{kg} / 24 \mathrm{hrs}$ of meloxicam (Boehringer Ingelheim, Rhein, Germany), a low selective anti-COX-2 agent ${ }^{28}$ were administered by intramuscular injection. Finally, in group E, doses of $0.5 \mathrm{mg} / \mathrm{kg} / 24 \mathrm{hrs}$ of rofecoxib (Merck, Whitehouse Station, New Jersey), a highly selective anti-COX-2 agent, ${ }^{28}$ were given orally. The doses were calculated by body-weight at a level equivalent to low therapeutic administration in man and doubled since the metabolic rate of anti-COX agents in animals is approximately twice as fast as that in man. ${ }^{29-31}$

All the animals were killed at six weeks, using a high intravenous dose of $0.5 \mathrm{~g}$ of Trapanal (Altana Pharma, Konstanz, Germany). Both ulnae were dissected and the mechanical properties and the histology of the site of the osteotomy were evaluated. The left ulna was used as a control. ${ }^{32}$ Serial lateral radiographs were taken post-operatively, at the first week and every week thereafter. At six weeks we recorded complete union as two cortices bridging the site of the osteotomy, incomplete union as one cortex bridging the site and nonunion as no bridging after a panel review of radiographs. The ratio of the diameter of the

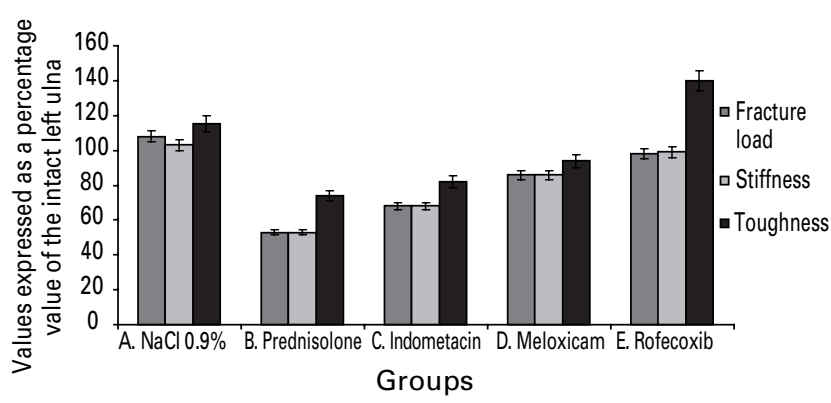

Fig. 1

Bar chart showing the mechanical parameters in all groups.

callus to the diameter of the bone $(\mathrm{dC} / \mathrm{dB})$ was also calculated. ${ }^{33}$

The mechanical properties of the bone were studied using a Karl-Frank computerised testing machine (KarlFrank, Basel, Switzerland). The specimens of both ulnae were kept wet in normal saline and the tests were performed within 20 minutes of harvesting. A three-point bending test, applying a low cross-head displacement rate of $0.05 \mathrm{~mm} / \mathrm{s}$, was used. ${ }^{18}$ The bending load was applied to the concave surface of the right ulna at the site of the osteotomy. On the left ulna the load was applied at the mid-shaft. The span (L) of loaded bone was $30 \mathrm{~mm}$ to guarantee that $85 \%$ to $90 \%$ of the flexion of the bone was caused by bending. Low fracture criteria were set at the level of $5 \mathrm{~N}$ in order to avoid structural damage to the specimens and to facilitate histomorphometric evaluation. Load/deflection curves were taken and from these the structural mechanical parameters of fracture load $(\mathrm{N})$, stiffness $(\mathrm{N} / \mathrm{mm})$ and toughness $(\mathrm{Nmm})$ were estimated. The values of all the mechanical parameters of the right ulna were recorded as a percentage of those of the contralateral intact ulna in an attempt to minimise the effect of genetic and anatomical variations in the animals. ${ }^{32}$

After the mechanical tests had been completed, the specimens of the right ulnae of all the animals were fixed in $10 \%$ buffered formalin. Using a low-speed diamond sawing machine, slices $5 \mathrm{~mm}$ thick were obtained including the fracture callus and normal cortex from both sides. The specimens were dehydrated in degraded alcohol and embedded in methylmethacrylate. Histological sections, $8 \mathrm{~cm}$ to $10 \mathrm{~cm}$ thick, were cut on a Polycut Model microtome (Leica, Heidelberg, Germany), and stained with Goldner (Bio-Optica, Milan, Italy). Histomorphometric measurements were calculated on light microscopy using a semi-automatised OsteoMeasure software program (Osteometrics, Atlanta, Georgia), adopting standardisation of nomenclature, symbols and units according to the American Society of Bone and Mineral Research (ASBMR) Histomorphometry Nomenclature Committee. ${ }^{34}$ The following primary parameters 
$\mathrm{NOb}$

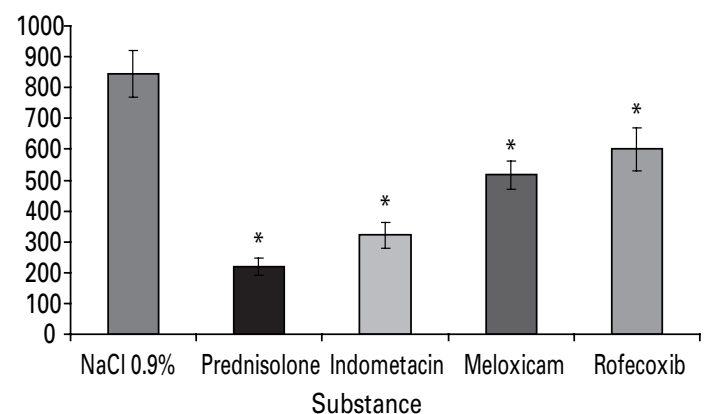

$\mathrm{ObS} / \mathrm{BS}$

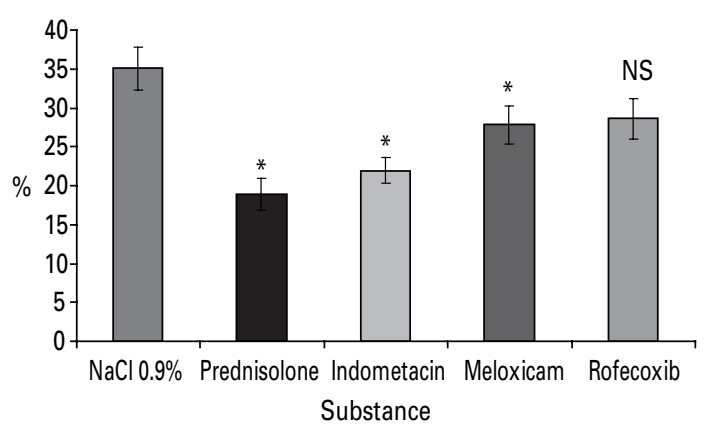

$\mathrm{NOb} / \mathrm{ObPm}$

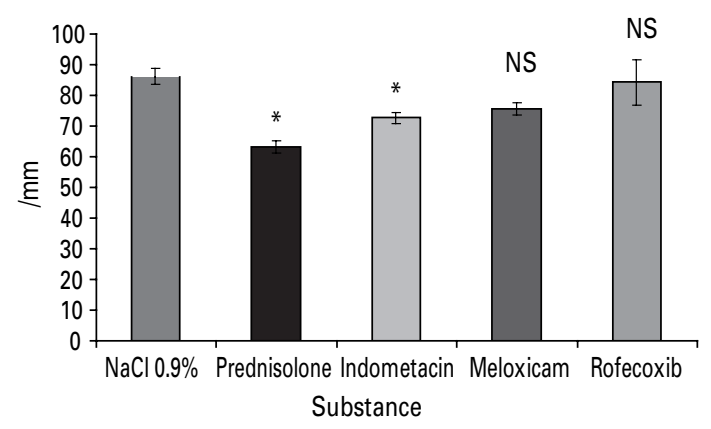

$\mathrm{ObPm}$
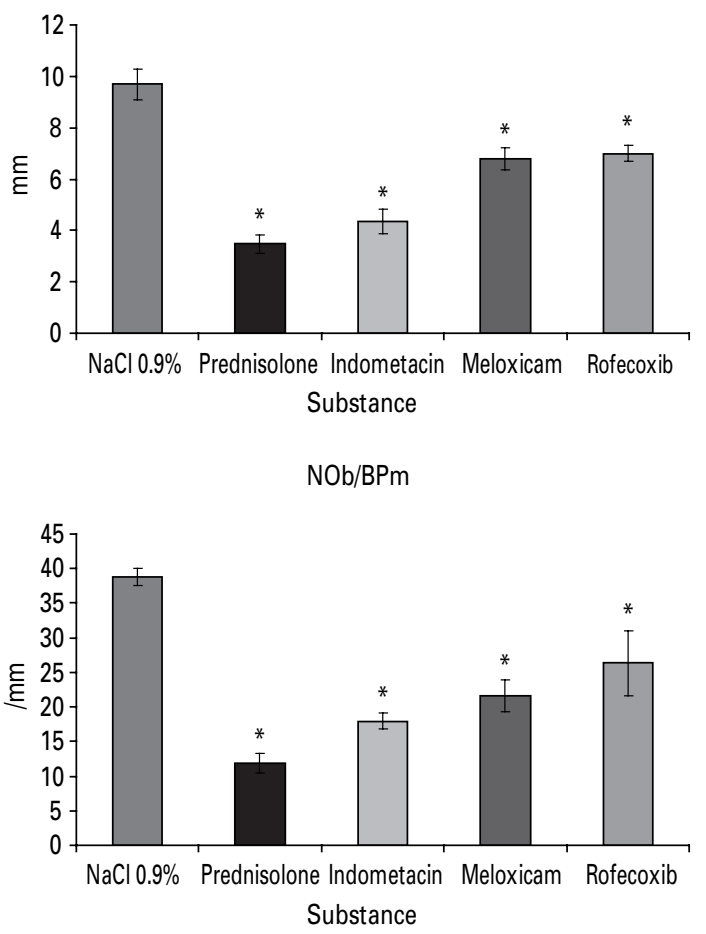

Fig. 2

Bar charts showing mean values \pm SEM (standard error of the mean) of the histomorphometric parameters related to the osteoblasts in all groups $(*$, statistically significant difference compared with control $(p \leq 0.05)$; NS, not significant; NOb, number of osteoblasts; ObPm, perimeter of the osteoblasts; ObS/BS, ratio of osteoblast to bone surface; NOb/BPm, number of osteoblasts/ bone perimeter; NOb/ObPm, number of osteoblasts/osteoblast perimeter).

and derived indices of the callus were evaluated: the number of osteoblasts $(\mathrm{NOb})$ and osteoclasts $(\mathrm{NOc})$, the perimeter of the osteoblasts $(\mathrm{OPm})$ and the osteoclasts $(\mathrm{OcPm})$, the ratio of the osteoblast $(\mathrm{ObS} / \mathrm{BS})$ or osteoclast $(\mathrm{OcS} / \mathrm{BS})$ to the bone surface, the number of osteoblasts $(\mathrm{NOb} / \mathrm{BPm})$ or osteoclasts $(\mathrm{NOc} / \mathrm{BPm}) /$ bone perimeter, the number of osteoblasts/osteoblast perimeter $(\mathrm{NOb} / \mathrm{ObPm})$, the number of osteoclasts/osteoclast perimeter $(\mathrm{NOc} / \mathrm{OcPm})$, the trabecular number $(\mathrm{TbN})$, the trabecular thickness $(\mathrm{TbTh})$ and trabecular separation (TbSp).
Statistical analysis. We used one-way analysis of variance (ANOVA) with or without previous transformations of the values. The normality and homogeneity of the measurements were tested by the Shapiro-Wilk and the Levene tests, respectively. ${ }^{35}$ For the identification of relative statistical differences between groups the Duncan test was also used..$^{35}$ For the analysis of the results we used the statistical software program SPSS for Windows version 11.5 (SPSS Inc., Chicago, Illinois) and all the tests were made with a level of significance of $\mathrm{p} \leq 0.05$. A post hoc statistical power analysis $^{36}(G *$ Power software for Windows version 2; Faul 

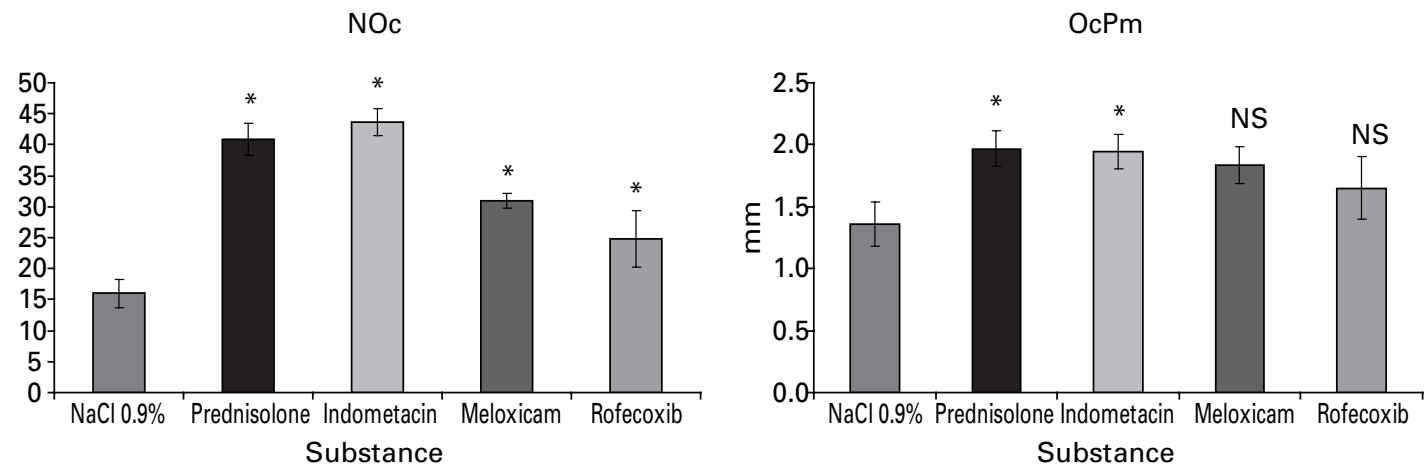

OcS/BS
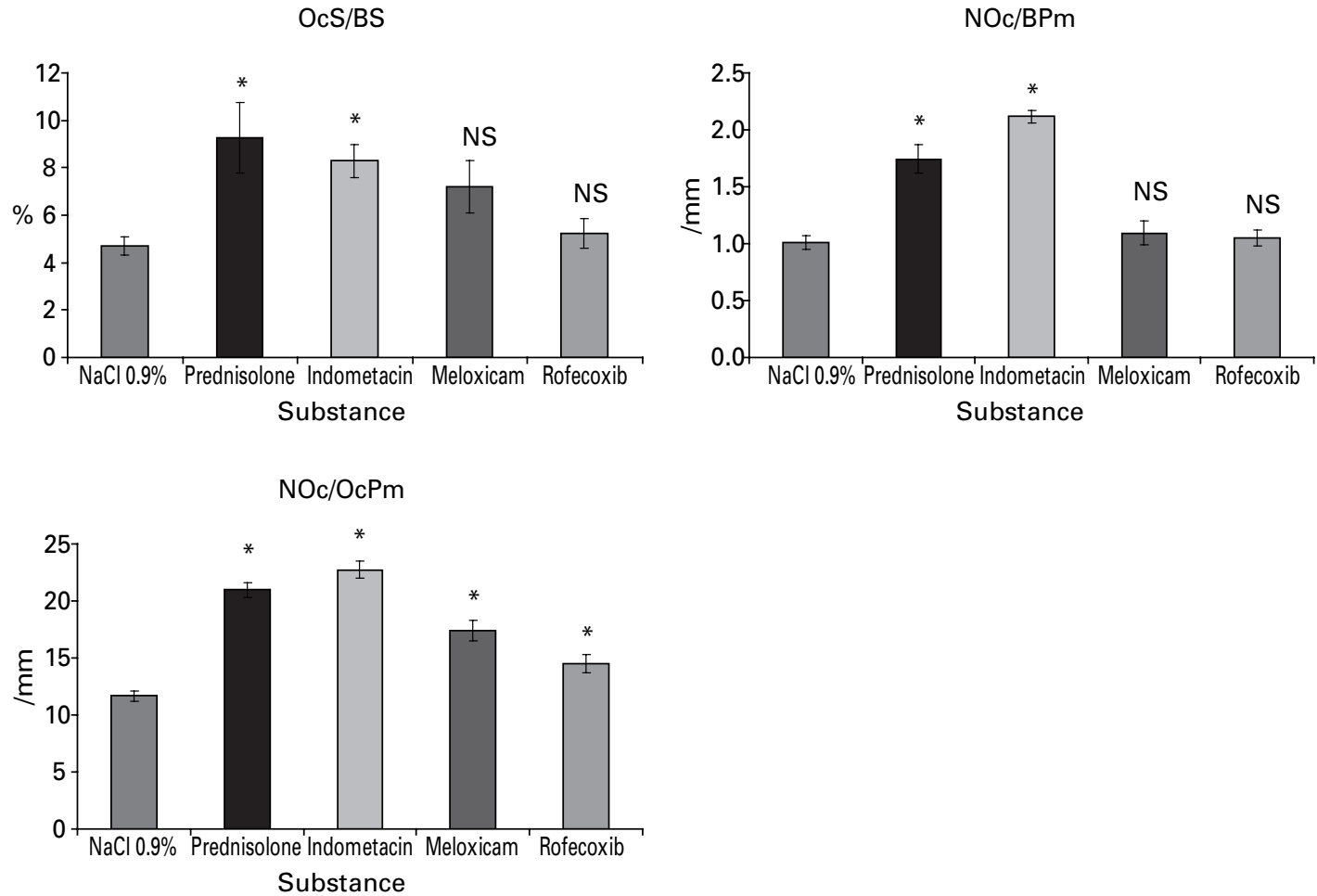

Fig. 3

Bar charts showing mean values \pm SEM (standard error of the mean) of the histomorphometric parameters related to the osteoclasts in all groups $\left({ }^{*}\right.$, difference compared with the control $(\mathrm{p} \leq 0.05)$; NS, not significant; NOc, number of osteoclasts; OcPm, perimeter of the osteoclasts; OcS/BS, ratio of osteoclast to bone surface; NOc/BPm, number of osteoclasts/bone perimeter; $\mathrm{NOc} / \mathrm{OcPm}$, number of osteoclasts/osteoclast perimeter).

and Erdfelder, Bonn, Germany) was also performed with a level of significance of $\alpha=0.05$. The power of the study for the biomechanical parameters ranged between $97 \%$ and $99 \%$, for the histomorphometric parameters between $77 \%$ and $99 \%$ and for the ratio $\mathrm{dC} / \mathrm{dB}$ it was $49 \%$.

\section{Results}

On radiological evaluation, the initial stages of formation of periosteal callus were apparent by two weeks, while signs of bridging of the site of the osteotomy appeared after the third post-operative week. The incidence of union, incomplete union and nonunion at six weeks in all groups is shown in Table I and the mean values of the ratio $\mathrm{dC} / \mathrm{dB}$ at six weeks in all groups in Table II. There were no statistically significant differences in the groups for this ratio.

The results of mechanical testing are shown in Figure 1. When specimens from group $\mathrm{E}$ (rofecoxib) were compared with those of group A (control), there were no statistically significant differences concerning the parameters of stiffness and toughness. Specimens from group E showed statistically significant (Duncan test, $\mathrm{p}<0.05$ ) lower values for fracture load compared with those of group A. Review- 


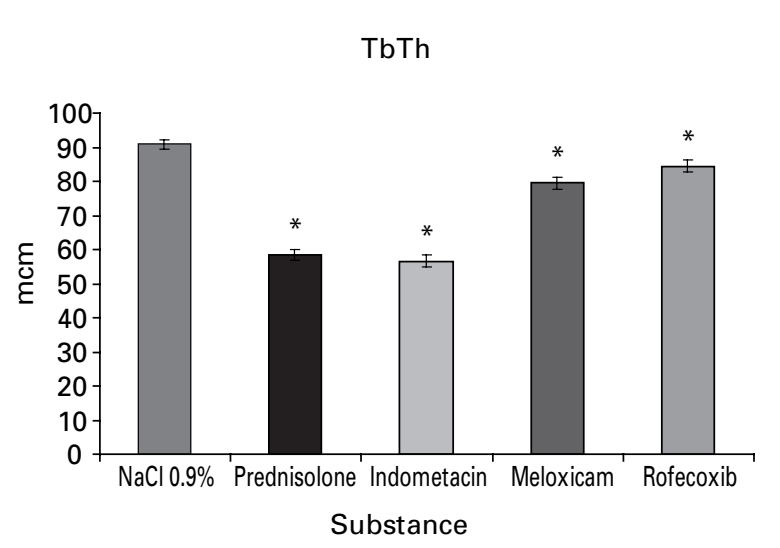

TbSp

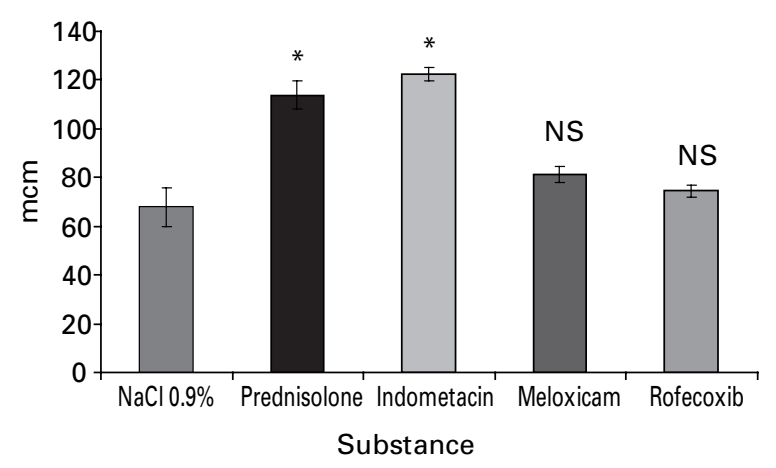

$\mathrm{TbN}$

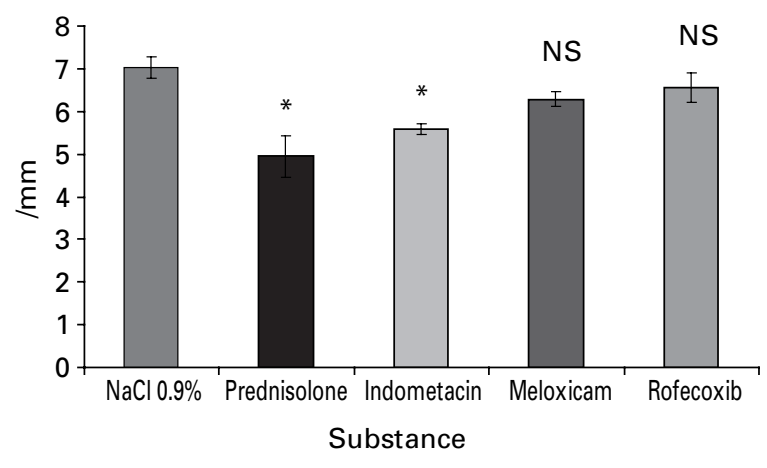

Fig. 4

Bar charts showing the mean values \pm SEM (standard error of the mean) of the histomorphometric parameters related to bone trabeculae in all groups $(*$, statistically significant difference compared with the control ( $p \leq 0.05)$; NS, not significant; TbTh, trabecular thickness; TbSp, trabecular separation; TbN, trabecular number).

ing all the mechanical parameters, specimens from groups B (prednisolone) and C (indometacin) showed statistically significant lower values (Duncan test, all p-values $=0.001$ ) when compared with those of groups A (control) and E (rofecoxib), while they showed statistically significant lower values (Duncan test, all p-values $=0.05$ ) when com-

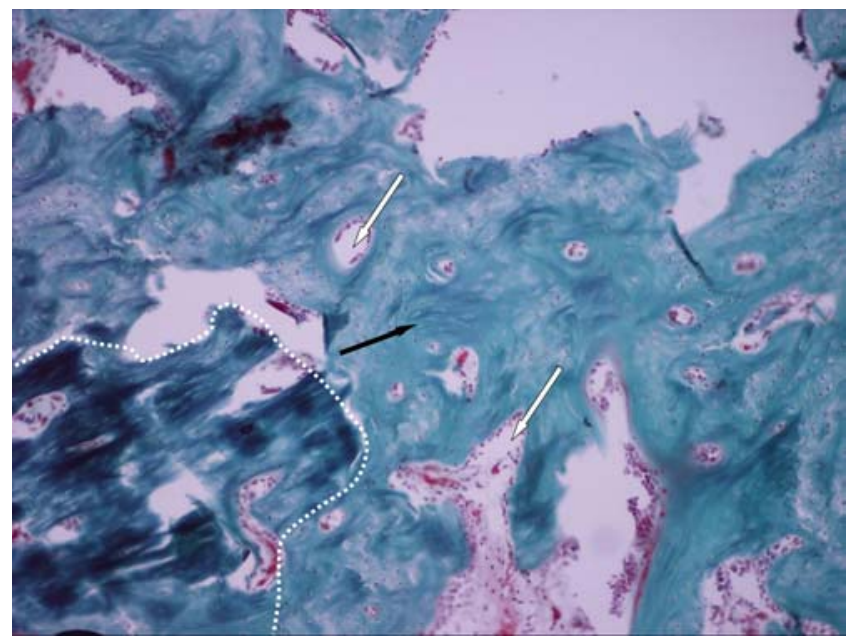

Fig. 5

Photomicrograph of a section from group $E$ (rofecoxib). In the lower left corner the site of the osteotomy is seen (dotted line) while the rest represents mature callus (black arrow) with the second phase of mineralisation completed. Larger and smaller remodelling units are apparent (white arrows) (Goldner staining $\times 10$ ).

pared with those of group D (meloxicam). Specimens from group E (rofecoxib) showed statistically significant (Duncan test, $\mathrm{p}=0.05$ ) higher values of all parameters when compared with those of group D (meloxicam).

The mean values and standard error of the mean (SEM) of all the histomorphometric parameters and relevant indices related to $\mathrm{NOb}, \mathrm{NOc}$ and bone trabeculae are shown in Figures 2 to 4, with statistically significant differences in the groups. At six weeks specimens from group B (prednisolone), $\mathrm{C}$ (indometacin), $\mathrm{D}$ (meloxicam) and $\mathrm{E}$ (rofecoxib) presented a statistically significant (Duncan test, $\mathrm{p}=0.05$ ) lower number of NOc, a higher number of NOc and thinner bone trabeculae compared with specimens in group A (control (Figs 2 to 4)). Specimens from groups B (prednisolone) and C (indometacin) when compared with group A (control) had statistically significant differences (Duncan test, $\mathrm{p}=0.05$ ) for all parameters and indices tested. When specimens from groups B (prednisolone) and C (indometacin) were compared, no statistically significant differences were found. When specimens of group D (menoxicam) were compared with those of group A (control) statistically significant differences (Duncan test, $p=0.05$ ) were found in seven of the 13 histomorphometric parameters and indices tested. Similarly, when specimens of group E (rofecoxib) (Fig. 5) were compared with those of group A (control) (Fig. 6) statistically significant differences (Duncan test, $\mathrm{p}=0.05$ ) were found in six of the 13 parameters and indices tested. Finally, when groups D (meloxicam) and E (rofecoxib) were compared statistically significant differences (Duncan test, $\mathrm{p}=0.05$ ) were found in only two parameters (TbTh and NOc/OcPm). 


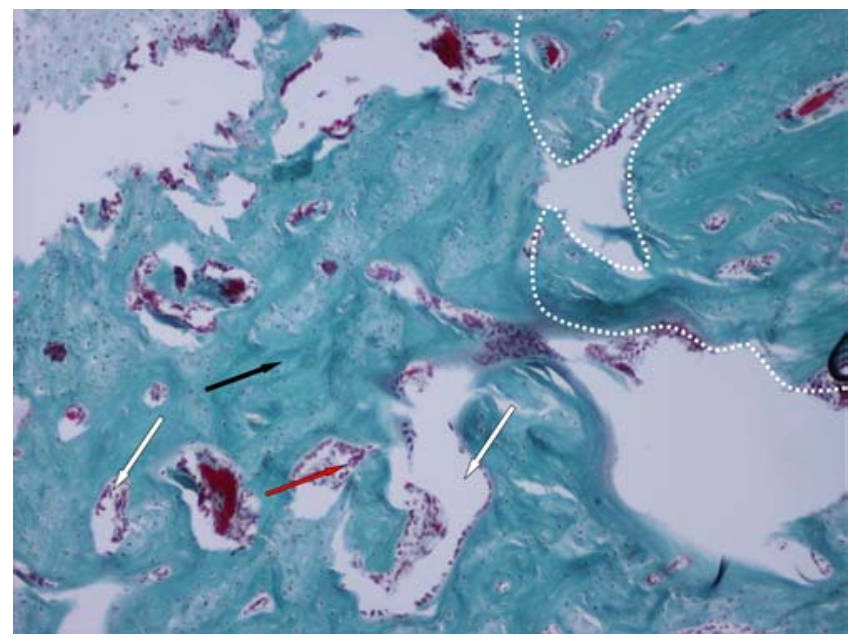

Fig. 6

Photomicrograph of a section from group $A$. In the upper right corner the site of the osteotomy is seen (dotted line) while the rest represents mature callus (black arrow) with the second phase of mineralisation completed. Remodelling units of different sizes are also observed (white arrows) with their surfaces covered by numerous osteoblasts (red arrow) (Goldner staining $\times 10$ ).

\section{Discussion}

The use of NSAIDs continues to expand because of the broad spectrum of their clinical application and the relatively recent introduction of the popular COX-2 selective inhibitors. ${ }^{1,4}$

Numerous studies over the last two decades have shown that conventional NSAIDs have an inhibitory effect on bone healing. ${ }^{4,8-15,17,37-40}$ The mechanism of action of NSAIDs is the inhibition of the COX enzyme which plays a central role in the metabolism of arachidonic acid. They inhibit the production of prostaglandins which are major factors in inflammation. ${ }^{1-5}$ Prostaglandins are synthesised by $\mathrm{NOb}$ and stimulate both the formation and resorption of bone. ${ }^{1}$ They play a role in the formation and function of NOc by stimulation of osteoclastogenesis through direct action on NOc precursors and by stimulation of bone resorption.

The COX enzyme has two distinct isoforms, COX-1 and COX-2. ${ }^{1-5}$ The COX-1 isoenzyme is active throughout the body and is responsible for several 'housekeeping' physiological functions, such as the maintenance of homeostatic levels of prostaglandins for the normal function of several organs, in particular the stomach. COX-2 is responsible for the regulation of prostaglandins and is induced by an array of stimuli, including pro-inflammatory cytokines, growth factors, mechanical stress, injury and inflammation. ${ }^{1,5}$ It is believed that the adverse gastrointestinal effects of these traditional agents are associated with the inhibition of COX-1, while the analgesic, antipyretic and anti-inflammatory effects are caused by inhibition of COX-2. Increase in the production of prostaglandins by bone cells is regulated by COX-2 expression. Conventional NSAIDs suppress both COX-1 and COX-2. It was hoped that the COX-2 selective inhibitors would be better tolerated and equally efficacious in managing inflammation. There are different levels of selectivity in anti-COX-2 action ${ }^{28}$ which is measured by the ratio of concentrations of the agents that are able to inhibit COX-1 and COX-2 at a level of $50 \%$ in vitro $\left(\mathrm{COX}-1 / \mathrm{COX}-2 \mathrm{IC}_{50}\right)$. Whereas the selective action of antiCOX-2 agents may allow inflammation to be inhibited with minimal effects on certain homeostatic mechanisms, their exact role in bone metabolism and fracture healing remains uncertain. It has been suggested that COX-2 regulates mesenchymal cell differentiation into the NOb lineage and is critically involved in bone repair. ${ }^{21}$ Since complete inhibition of the process of bone healing has been observed in mice which generally lack COX-2, it seems that COX-2 is essential for bone healing. ${ }^{20,22}$ Recent studies have focused on the efficacy and the adverse effects of novel COX-2 inhibitors, especially evaluating their possible negative effect on fracture healing. ${ }^{11,16,19,20,23,24}$ Although a few studies suggest that there is minor or no impairment of the healing process, ${ }^{11,23,24}$ most of the data indicates that in animal models COX-2 inhibitors impair bone healing. ${ }^{1,2,4,5,20}$ The inhibitory effect of dexamethasone, indometacin and ketorolac on experimental spinal fusion in rabbits has been demonstrated, ${ }^{41-44}$ with celecoxib showing minor inhibitory effects in similar experimental conditions. ${ }^{45}$ There are currently no published prospective studies in man addressing the same question, and the only existing retrospective study suggests a marked association of nonunion with the use of NSAIDs in patients with fracture of the femoral shaft. ${ }^{46}$

Evaluation of existing animal studies shows that the COX-2 inhibitors were used in high doses and for extended periods of time. These do not mimic the conditions for application in man. ${ }^{1,16,19,20}$ There is also evidence that the effects of COX-2 inhibitors are both dose-dependent and reversible. ${ }^{3,9}$ All the studies used the rat femoral fracture model and most of them employed an intramedullary rod for fixation of the experimental fracture, which represents secondary osteonal healing. ${ }^{25}$ In order to obtain information more clinically relevant to man we used a larger animal model, ${ }^{24,26}$ an ulnar osteotomy, which is a relatively difficult healing environment ${ }^{47}$ and union by secondary (non osteonal) healing. ${ }^{24-26} \mathrm{~A}$ steroid and a low selective (meloxicam, COX-1/COX-2 $\mathrm{IC}_{50}$ of 6$)^{28}$ and a high selective (rofecoxib, COX-1/COX-2 IC $_{50}$ of 137 ) ${ }^{28}$ NSAID were used for comparison. The doses of steroid and NSAIDs were set to be equivalent to the low therapeutic doses administered to man, bearing in mind that the metabolic rate of NSAIDs is higher in animals. ${ }^{29-31}$ The duration of administration was set at the level of five days in order to mimic short-term analgesic and anti-inflammatory regimes in patients who have sustained fractures. The duration of the biomechanical and histomorphometric studies was six 
weeks in order to evaluate callus and fracture healing at a progressing stage $e^{26}$ and to reflect the effect of discontinuation of the agents studied.

The short-term administration of prednisolone, indometacin and meloxicam in the early stages of the healing process caused a delay in the appearance of the radiological union of the osteotomies, with $50 \%$ of the animals showing delayed union when taking prednisolone and indometacin and $37.5 \%$ when taking meloxicam. By contrast, the selective anti-COX-2 agent rofecoxib did not affect radiological union, with $75 \%$ of the animals showing complete union, a similar rate of union as was observed in the control group. No agents tested in our study caused nonunion at the site of the osteotomy.

The short-term administration of prednisolone in the early stages of healing adversely affected the biomechanical and histomorphometric parameters of the site of the osteotomy, a finding similar to that found by Waters et al. ${ }^{27}$ The biomechanical parameters were reduced by $50 \%$ when compared with those of the control group and histomorphometric examination showed a reduction in osteoblastic activity. The short-term administration of indometacin reduced the biomechanical parameters by a level of $30 \%$ to $35 \%$ when compared with those of the control group, and all histomorphometric assessment indicated delayed union of the osteotomy, as described previously. ${ }^{8,10,14,20,38-40}$ Indometacin reduced osteoblastic activity less than prednisolone and prednisolone diminished osteoclastic activity and the structural integrity of the trabeculae less than indometacin. The adverse effect of meloxicam on healing was less apparent. Rofecoxib, a highly selective anti-COX-2 agent, caused a minor delay in healing affecting only the histomorphometric parameters.

Our study has shown that the administration of a selective anti-COX-2 in low therapeutic doses and for a short period of time is safe and that it does not affect the late stages of secondary non-osteonal bone healing. However, when celecoxib was administered for ten days it had a negative effect on fractures of the femur in a rat model. ${ }^{48}$ Selective anti-COX-2 agents may have a dose-dependent negative effect at the initial stages of fracture healing $3,11,48$ which reverses when administration is discontinued. ${ }^{1,3}$ Our study has shown that the more selective the anti-COX-2 agent is, the less negative is the effect on bone healing. Prostaglandins which are produced at the site of the fracture have a significant role in healing. It is not clear if their production is controlled by COX-2 exclusively or if a local production of COX-1 is also important. It is possible that local COX-1 protects healing and local or systematic variations in the production of prostaglandins from COX-1 and COX-2 may lead to different biological responses which affect the healing of musculoskeletal tissues. ${ }^{3,11}$

The possibility of administering anti-COX-2 agents to patients with fractures needs to be assessed in randomised clinical trials. This will be difficult, however, because of ethical issues and difficulties in the recruitment of patients to a study which tests the ability of a drug to inhibit healing, resulting from recent concerns regarding cardiovascular toxicity and difficulties in the grouping of individual fracture patterns, the assessment of healing and the identification of end-points.

It seems that COX-2 is essential for bone healing and its long-term inhibition with high doses of anti-COX-2 agents may impair healing as do the corticosteroids, the classic NSAIDs and the low selective anti-COX-2. However, the short-term administration of therapeutic doses of high selective anti-COX-2 agents has a minor effect on the late stages of secondary bone healing.

No benefits in any form have been received or will be received from a commercial party related directly or indirectly to the subject of this article.

\section{References}

1. Einhorn TA. Do inhibitors of Cyclooxygenase-2 impair bone healing. J Bone Miner Res 2002;17:977-8.

2. Gajraj NM. The effect of cyclooxygenase-2 inhibitors on bone healing. Reg Anesth Pain Med 2003:28:456-65

3. Gerstenfeld LC, Einhorn TA. COX inhibitors and their effects on bone healing. Expert Opin Drug Saf 2004;3:131-6.

4. Harder AT, An YH. The mechanisms of the inhibitory effects of nonsteroidal antiinflammatory drugs on bone healing: a concise review. J Clin Pharmcol 2003;43:80715.

5. Seidenberg AB, An YH. Is there an inhibitory effect of COX-2 inhibitors on bone healing? Pharmacol Res 2004;50:151-6.

6. Fitzgerald GA, Patrono C. The coxibs, selective inhibitors of cyclooxygenase-2. N Engl J Med 2001;345:433-42.

7. Gilroy DW, Colville-Mash PR. New sights into the role of COX-2 in inflammation. J Mol Med 2000;78:121-9.

8. Altman RD, Latta LL, Keer R, et al. Effect of nonsteroidal anti-inflammatory drugs on fracture healing: a laboratory study in rats. J Orthop Trauma 1995:9:392-400.

9. Beck A, Krischak G, Sorg T, et al. Influence of diclofenac (group of nonsteroidal anti-inflammatory drugs) on fracture healing. Arch Orthop Trauma Surg 2003;123:32732.

10. Engesaeter LB, Sudmann B, Sudmann E. Fracture healing in rats inhibited by locally administered indomethacin. Acta Orthop Scand 1992;63:330-3.

11. Gerstenfeld LC, Thiebe $\mathbf{M}$, Seibert $K$, et al. Different inhibition of fracture healing by non-selective and cyclooxygenase-2 selective non-steroidal anti-inflammatory drugs. J Orthop Res 2003;21:670-5.

12. Giordano V, Giordano M, Knackfuss IG, Apfel MIR, Gomes RDC. Effect of tenoxicam on fracture healing in rat tibiae. Injury 2003;34:85-94.

13. Hogevold HE, Grogaard B, Reikeras $\mathbf{0}$. Effects of short term treatment with corticosteroids and indomethacin on bone healing: a mechanical study of osteotomies in rats. Acta Orthop Scand 1992;63:607-11.

14. Hogevold HE, Grogaard B, Reikeras $\mathbf{0}$. The effects of short term and long term treatment with indomethacin on primary and secondary fracture healing in rats. Eur $J$ Exp Musculoskeletal Res 1993;2:3-8.

15. Huo MH, Troiano NW, Perker RR, Gundberg CM, Friedlaender GE. The influence of ibuprofen on fracture repair: biomechanical, biochemical, histologic and histomorphometric parameters in rats. J Orthop Res 1991;9:383-90.

16. Leonelli S, Goldberg B, Safanda J, et al. The effect of cyclooxygenase 2 (COX-2) inhibitors on bone healing. Am J Orthop 2006;35:79-84.

17. Tornkvist $\mathbf{H}$, Lindholm TS. Effect of ibuprofen on mass and composition of fracture callus and bone: an experimental study on adult rat. Scan J Rheumatol 1980;9:16771

18. Turner CH, Burr DB. Basic biomechanic measurements of bone: a tutorial. Bone 1993;14:595-608

19. Endo K, Sairyo K, Komatsubara $\mathbf{S}$, et al. Cyclooxygenase-2 inhibitor inhibits the fracture healing. J'Physiol Anthropol Appl Human Sci 2002;21:235-8.

20. Simon AM, Manigrasso MB, O'Connor JP. Cyclo-oxygenase-2 function is essential for bone fracture healing. J Bone Miner Res 2002;17:963-76.

21. Zhang $\mathbf{X}$, Xing L, Boyce BF, et al. COX-2 is critical for mesenchymal cell differentiation during skeletal repair. J Bone Miner Res 2001;16:145.

22. Zhang X, Schwarz EM, Young DA, et al. Cyclooxygenase-3 regulated mesenchymal cell differentiation into the osteoblast lineage and is critically involved in bone repair. J Clin Invest 2002;109:104-15. 
23. Brown KM, Saunders MM, Kirsch T, Donahue HJ, Reid JS. Effect of COX-2-specific inhibition on fracture healing in the rat femur. J Bone Joint Surg [Am] 2004;86A:116-23.

24. Mullis B, Copeland S, Weinhold P, et al. Effect of COX-2 inhibitors and NSAIDs on fracture healing in a mouse model. Injury 2006;37:827-37.

25. Chao EY, Aro HT, Lewallen DG, Kelly PG. The effect of rigidity on fracture healing in external fixation. Clin Orthop 1989;241:24-35.

26. Karachalios T, Scambardonis D, Khaldi L, et al. Influence of orthotopic placement on the incorporation and mechanical strength of a loaded structural cortical graft: an experimental study in rabbits. Orthopaedics 2000;23:815-21.

27. Waters RV, Gamradt SC, Asnis P, et al. Systemic corticosteroids inhibit bone healing in a rabbit ulnar osteotomy model. Acta Orthop Scand 2000;71:316-21.

28. Warden SJ. Cyclo-oxygenase-2 inhibitors: beneficial or detrimental for athletes with acute musculoskeletal injuries? Sports Med 2005:35:271-83.

29. Halpin RA, Geer LA, Zhang KE, et al. The absorption, distribution, metabolism and excretion of rofecoxib, a potent and selective cycloxygenase-2 inhibitor, in rats and dogs. Drug Metal Dispos 2000;28:1244-54.

30. Depre M, Ehrich E, van Hecken A, et al. Pharmacokinetics, COX-2 specificity, and tolerability of supratherapeutic doses of rofecoxib in humans. Eur J Clin Pharmacol 2000;56:167-74.

31. Busch U, Schmid J, Heinzel G, et al. Pharmacokinetics of meloxicam in animals and the relevance to humans. Drugs Metab Dispos 1998;6:576-84.

32. An YH, Kang Q, Friedman RJ. Mechanical symmetry of rabbit bones studied by bending and indentation testing. Am J Vet Res 1996;57:1786-9.

33. Marsh D. Concepts of fracture union, delayed union and nonunion. Clin Orthop 1998;355:22-30

34. Parfitt AM, Drezner MK, Glorieux FH, et al. Bone histomorphometry: standardization of nomenclature, symbols and units. J Bone Miner Res 1987;2:595-610.

35. Altman DG. Practical statistics for medical research. London: Chapman and Hall 1993.

36. Cohen J. Statistical power analysis for behavioral sciences. New Jersey: Laurence Erlbaum Associates Inc., 1988.
37. Ho ML, Chang JK, Chuang LY, Hsu HK, Wang GJ. Effects of nonsteroidal antiinflammatory drugs and prostaglandins on osteoblastic functions. Biochem Pharmcol 1999;58:983-90.

38. Keller J. Effects of indomethacin and local prostaglandin E2 on fracture healing in rabbits. Dan Med Bull 1996;43:317-29.

39. Reikeras 0, Engebretsen L. Effects of ketoralac tromethamine and indomethacin on primry and secondary bone healing: an experimental study in rats. Arch Orthop Trauma Surg 1998;118:50-2.

40. Sudmann E, Dregelid E, Bessesen A, Morland J. Inhibition of fracture healing by indomethacin in rats. Eur J Clin Inv 1979;9:333-9.

41. Sawin PD, Dickman CA, Crawford NR, et al. The effects of dexamethasone on bone fusion in an experimental model of posterolateral lumbar spinal arthrodesis. $J$ Neurosurg 2001;94:76-81.

42. Dimar JR II, William A, Ante BS, Zhang YP, Glassman SD. The effects of nonsteroidal anti-inflammatory drugs on posterior spinal fusions in the rat. Spine 1996:21:1870-6.

43. Riew KD, Long J, Rhee J, et al. Time-dependent inhibitory effects of indomethacin on spinal fusion. J Bone Joint Surg [Am] 2003;85-A:632-4.

44. Martin GJ, Boden SD, Titus L. Recombinant human bone morphogenetic protein-2 overcomes the inhibitory effects of keterolac, a nonsteroidal anti-inflammatory drug (NSAID), on posterolateral lumbar intertransverse process spine fusion. Spine 1999;24:2188-94.

45. Long J, Lewis S, Kuklo T, Zhu Y, Riew KD. The effect of cyclooxygenase-2 inhibitors on spinal fusion. J Bone Joint Surg [Am] 2002;84-A:1763-8.

46. Giannoudis PV, MacDonald DA, Mathews $\mathbf{S} J$, et al. Nonunion of the femora diaphysis: the influence of reaming and nonsteroidal anti-inflammatory drugs. J Bone Joint Surg [Br] 2000;82-B:655-8.

47. Park SH, O'Connor K, Sung R, Sarmiento A. Comparison of healing process in open osteotomy model and closed fracture model. J Orthop Trauma 1999;13:114-20.

48. Bergenstock M, Min W, Simon AM, Sabatino C, O'Connor JP. A comparison between the effects of acetaminophen and celecoxib on bone fracture healing in rats. J Orthop Trauma 2005;19:717-23. 